\title{
Novel mass air flow meter for automobile industry based on thermal flow microsensor. I. Analytical model and microsensor
}

\author{
Oleg Sazhin * \\ Ural Federal University, Lenin av. 51, Ekaterinburg 620083, Russia
}

\section{A R T I C L E I N F O}

\section{Article history:}

Received 30 June 2012

Received in revised form

21 December 2012

Accepted 6 January 2013

Available online 16 January 2013

\section{Keywords:}

Thermal flow sensor

Mass flow rate

Heat and mass transfer

Mass flow meter

MEMS

\begin{abstract}
A B S T R A C T
An analytical model of the thermal flow sensor has been developed. The results of analytical model application are utilized to develop a thermal flow microsensor with optimal functional characteristics. The technology to manufacture the microsensor is described. A prototype of the microsensor suitable to be used in the mass air flow meter has been designed. The basic characteristics of the microsensor are presented.
\end{abstract}

(c) 2013 Elsevier Ltd. All rights reserved.

\section{Introduction}

So-called thermal flow sensors [1-3] holds a special place among modern microelectromechanical systems (MEMS), their general operation principle is based on dependency of intensity of convective heat transfer on velocity of the moving medium (fluid). The study of patents database shows an increasing interest in recent years for the development of new thermal flow microsensors design, which is based on the use of technologies to form micro- and nano-scale surface structures (see, for example, [4]). Indeed, due to fast-evolving methods of surface microstructure formation with enhanced exploitation characteristics a significant progress has been reached in the majority of critical industrial technologies as well as in microsensor manufacturing technology. In particular, miniaturization of the sensors has given new possibilities for their practical use, significantly reducing manufacturing cost and consumed electric energy.

Automobile [5-7], chemical [8] and electronic [9], medical [10] and aerospace [11] applications, air conditioning and ventilation [12] as well as other fields use thermal flow microsensors. Lately thermal flow microsensors are also used in Micro Total Analysis System ( $\mu$ TAS) [13] which has been significantly developed.

According to measuring principle the thermal flow sensors can be classified into three main categories: time of flight (TOF) sensors, thermal anemometers and calorimetric sensors.

\footnotetext{
* Tel.: +7 9049833920 .

E-mail addresses: oleg.sazhin@uralmail.com,olegsazhin@freemail.ru
}

The method to measure fluid velocity or fluid flow rate by using TOF sensors consists in determining the time delay of thermal pulse. The heater undergoes the pulse heating, and after some time (time of flight) temperature sensitive element located downstream the fluid flow, registers the pulse. Obviously the time of flight depends on the velocity of the fluid.

Thermal anemometers are among of the most common sensors to diagnose the fluid flow rate; they have quite a number of practical applications. In particular, the substance of one of them is to determine the dynamics of the electrically heated element that cools down as a result of heat exchange with the fluid. The heat exchange rate, in turn, depends significantly on the flow rate of the fluid. Since the electrical resistance of the most materials depends significantly on the temperature, the resistance of the material is measured to determine the temperature.

The principle of the calorimetric sensor is based on the change of the temperature field near the heated element through fluid flow. The difference of temperature between the temperature sensitive elements situated symmetrically downstream and upstream with reference to the heater is determined by the flow rate of the fluid.

Sensors based on a combination of the aforementioned measuring principles have also been developed. The calorimetric sensor is more sensitive to small flows, whereas thermal anemometers and TOF sensors are rather suitable for the diagnosis of large flows. Flow sensors based on a combination of calorimetric and TOF measuring principles are presented in works $[14,15]$. The method of detecting air flows in a wide range with defining the flow direction is presented in [16]: the measurement of small 
flows is based on the principle of change of difference and average temperature of the two temperature sensitive elements, while measurement of larger flows is based on the thermal anemometer principle. Two electrically heated, independent, parallel hot wires over a small cavity are used to measure the direction and the absolute value of the wall shear stress in a wide range [17].

Noteworthy is a thermal anemometer microsensor for measuring liquid and gas flow rates developed in [18]. Due to low heat capacity this microsensor can also be used for the dynamic measurements in liquids, e.g. for measuring pulsations in the flow with frequencies up to several hundred Hertz.

In general, depending on the needs of the practice, thermal flow microsensors can be used to measure small gas flow rate from $0.01 \mathrm{ml} / \mathrm{min}$ [19] up to the values of a few $1 / \mathrm{min}$, as in [20-22]. The value of maximum gas flow rate to be measured can be significantly increased by registering a split flow, where the percentage of flow going over the sensor is known with respect to the total flow rate. In particular, this approach is implemented in Bosch HFM5 mass air flow meter, which allows measuring the mass flow rate of air up to $10^{3} \mathrm{~kg} / \mathrm{h}\left(1.4 \times 10^{4} \mathrm{l} / \mathrm{min}\right)$, with relative error of less than $3 \%$, in the tube with inner diameter of $82 \mathrm{~mm}$ [7].

An important characteristic of the thermal flow sensor is its sensitivity. In particular, the sensitivity of the calorimetric flow sensor is determined as follows:

$S_{c}=\left.\frac{\partial \Delta T}{\partial Q}\right|_{Q=0}$,

where $\Delta T$ is the difference of the temperatures of temperature sensitive elements situated symmetrically downstream and upstream of fluid flow relative to the heater, and $Q$ is mass flow rate of the fluid.

In work [23] the sensitivity of the calorimetric flow sensor was examined experimentally and numerically. It is shown that the position of temperature sensitive elements, the size of the heater and the electrical power supplied to the heater significantly affect the sensitivity of the sensor. Work [24] has shown experimentally that the sensitivity of the calorimetric flow sensor also depends on the range of measured flow rate: the lower the range, the higher the sensitivity.

In addition, sensitivity of the sensor is significantly affected by thermal insulation of temperature sensitive elements from the substrate: the better thermal insulation is, the higher is sensitivity. Currently the decrease of "parasitic" effect of the substrate is carried out by using new technological methods and materials. In particular in work [25] a method for forming a substrate with high thermal resistance based on porous silicon was suggested. Indeed, the thermal conductivity of porous silicon depending on the size of the pores and the morphology of the material is in the range between 0.1 and $2 \mathrm{~W} / \mathrm{m} / \mathrm{K}$, which is significantly lower than thermal conductivity of polycrystalline silicon (about $170 \mathrm{~W} / \mathrm{m} / \mathrm{K}$ ) that is widely used in microelectronics [26]. Besides porous silicon other materials with low thermal conductivity are used, e.g. glass (quartz or Pyrex) and silicon dioxide with thermal conductivity of each about $1-1.4 \mathrm{~W} / \mathrm{m} / \mathrm{K}$ are used.

An effective way to achieve good thermal insulation by technological means is to create an air cavity that separates thin dielectric bearing structure with the temperature sensitive elements from the massive substrate [27]. Indeed, the thermal conductivity of air which is about $0.03 \mathrm{~W} / \mathrm{m} / \mathrm{K}$ is very low value compared to the thermal conductivity of solids, and the total thermal resistance of the substrate will be high. Obviously a good thermal insulation can also significantly reduce electric power consumed by the sensor.

In this paper we will focus on the calorimetric flow microsensor, since its practical implementation can combine all three

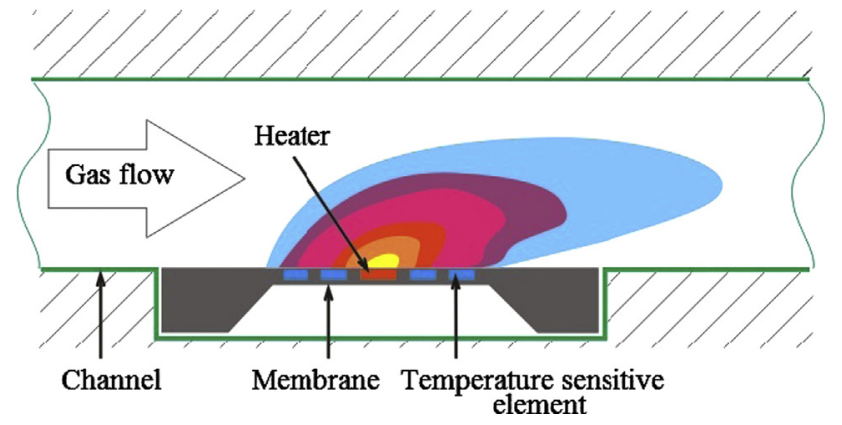

Fig. 1. The physical principle for diagnostics of the gas flow in a channel using a calorimetric sensor.

mentioned principles of measuring velocity and flow rate of the fluid. Fig. 1 illustrates the physical principle to diagnose gas flow in a channel using a calorimetric sensor. The sensor is mounted securely inside the channel either on the surface or at some distance. The measuring part of the sensor is a thin membrane that is situated on a massive substrate. Heater and temperature sensitive elements, number of which can be two or more, are enclosed inside the membrane.

From theoretic point of view to describe the heat and mass transfer process in internal gas flow is quite challenging. Indeed, the process of heat and mass transfer in channels depends on multiple factors such as the regime of the gas flow [28], the type and the size of the channel [29,30], the chemical composition of the channel's surface and the kind of gas [31-33], temperature distribution on the surface [34], roughness of the surface [35] and the pressure ratio [36]. The heat and mass transfer is also influenced by the macroscopic and physical properties of the gas.

There is no doubt for a more accurate and precise study of the heat and mass transfer process it is preferable to use numerical methods, such as the Finite Element Method (FEM), which is free from a number of assumptions and simplifications inherent in the analytical approaches. However for better understanding of the issue and recommendations to develop design of the sensor, analytical model is also highly critical.

The analytical model of the calorimetric sensor suggested in [37] is a frequently used model. According to this model the temperature of the membrane equals to the temperature of the environment at an infinite distance from the heater. However in reality the temperature of thin membrane equals the temperature of the environment at a finite distance from the heater, where it is connected to the massive substrate.

The theoretical purpose of this study is to develop a realistic analytical model of the calorimetric flow sensor suitable for engineering calculations. The results of such calculations may be provisional data of the functional characteristics of the sensor, identification of the most crucial parts of the system, comparison of several alternative designs, system optimization and calculation of operating regimes. The practical goal of this study is to develop and design a calorimetric microsensor with functional and technological characteristics as close as possible to the optimal ones.

\section{Analytical model}

Let us consider a membrane in the form of a thin rectangular plate with cross section of area $S$ and perimeter $p$ (Fig. 2). The plate is assumed to be so thin and wide that the temperature at all points of the cross section can be considered equal and side effects can be neglected. This allows us to use a one-dimensional formulation of the task. Consider the plate located on the $X$-axis 


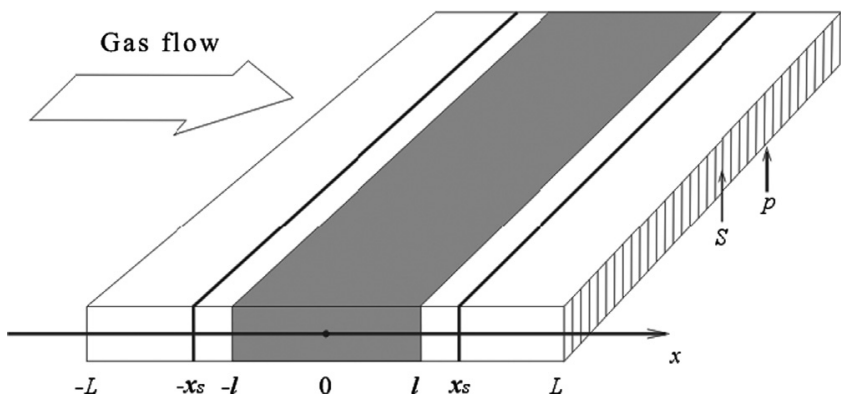

Fig. 2. Membrane. A thin rectangular plate with $2 L$ length and cross section of area $S$ and perimeter $p$, streamlined by the gas flow. Heater is located in the zone $-l \leq x \leq l$ and temperature sensitive elements are located in $-L<x_{s}<-l$ and $l<X_{S}<L$.

along which the gas flows with velocity $U$. The length of the plate in the $x$-direction is $2 L$, the length of the heater is $2 l$. Electrical power $P$ is applied upon the heater. Temperature sensitive elements are located in $-L<x_{s}<-l$ and $l<x_{s}<L$ areas.

In order to calculate the steady-state temperature distribution in the plate we can use a differential equation of heat conduction for an element volume, bounded by the sections passing through $x$ and $d x$ perpendicular to the $X$-axis:

$\frac{\lambda}{\rho c} \frac{\partial^{2} T}{\partial x^{2}}-U \frac{\partial T}{\partial x}-\frac{H p}{\rho c S}\left(T-T_{a m b}\right)+\frac{P}{2 l \rho c S}=0$,

where $T=T(x)$ is the temperature of the plate; $T_{a m b}$ is the temperature of the ambient environment; $H$ is the coefficient of the heat exchange between the gas and the plate, $\rho, c$ and $\lambda$ are the density, specific heat capacity and the coefficient of thermal conductivity of the plate material, respectively. In this equation the first term accounts the internal heat conduction, the second term conforms heat exchange by convection, the third term describes heat exchange with the surrounding gas, and the fourth is internal heat generation. The boundary conditions for this equation are set in the following way:

$\left\{\begin{array}{c}-L \leq x<-l: P=0, T(x=-L)=T_{a m b} ; \\ -l \leq x \leq l: P \neq 0, T(x=-l)=T_{(-l)}, T(x=l)=T_{l} ; \\ l<x \leq L: P=0, T(x=L)=T_{a m b} .\end{array}\right.$

In practice, one of the main problems of studying the heat transfer process in the "fluid-solid" system is determining a correct heat exchange coefficient $H$, which depends on many factors. In particular, fluid flow regime has a significant effect on the efficiency of the heat exchange, since it determines the mechanism of the heat transfer. In the laminar flow of the fluid the particles move without mixing so the heat transfer along the normal to the direction of motion is carried out by thermal conductivity. In the turbulent flow, the particles move randomly; motion direction and velocity of individual particles are continuously changing and the heat transfer along the normal to the average flow direction is carried out both by thermal conductivity and by convection, where convective heat transfer can significantly exceed heat exchange by thermal conductivity.

To solve the problem of the heat transfer in full, in order to determine the coefficient of heat exchange, a joint solution should be found for the equations of continuity, motion (Navier-Stokes) and energy transfer. Solving these equations simultaneously is quite complicated, so it is practical to use methods of the similarity theory.

Correlation equation for the heat transfer processes in the forced motion of the fluid is as follows

$N u=f(\operatorname{Re} ; \operatorname{Pr})$, where $\mathrm{Nu}, \mathrm{Re}$ and $\mathrm{Pr}$ are the similarity parameters: Nusselt, Reynolds and Prandtl number, respectively.

For the flow passing a plate with a uniform temperature within a cylindrical channel of $D$ diameter, a correlation equation can be written as a system of equations for each of the flow regimes as follows [38]:

$N u=\left\{\begin{array}{c}0.664 \operatorname{Re}^{1 / 2} \operatorname{Pr}^{1 / 3} \text { for laminar regime; } \\ \left(0.037 \operatorname{Re}^{4 / 5}-A\right) \operatorname{Pr}^{1 / 3} \text { for mixed regime; } \\ 0.037 \operatorname{Re}^{4 / 5} \operatorname{Pr}^{1 / 3} \text { for turbulent regime, }\end{array}\right.$

where $A=0.037 \mathrm{Re}_{c r}^{4 / 5}-0.664 \mathrm{Re}_{c r}^{1 / 2}, \quad R e_{c r}$ is critical Reynolds number.

The similarity parameters in this system of equations can be written as

$\left\{\begin{array}{c}N u=H 2 L / \lambda_{f} \\ R e=U D / v_{f} \\ \operatorname{Pr}=\eta_{f} c_{p f} / \lambda_{f},\end{array}\right.$

where $\lambda_{f}$ is the coefficient of thermal conductivity of the fluid, $v_{f}$ and $\eta_{f}$ are its kinematic and dynamic viscosities; $c_{p f}$ is the fluid specific heat capacity at constant pressure. Note that since the membrane is inside the channel, the heat exchange coefficient depends on the hydrodynamic gas flow pattern in the channel. Therefore, it is advised to choose the diameter of cylindrical or the height of rectangular channel in determining Re Reynolds number.

The transition from laminar to turbulent flow occurs when the critical $R e_{c r}$ Reynolds number is reached. When $R e<R e_{c r}$, the fluid flow occurs in the laminar regime. When $R e>R e_{c r}$, the turbulence may be experienced. $R e_{c r}$ critical Reynolds number for the fluid flow in a cylindrical channel approximately equals to 2300 . The fully developed turbulent regime is established at values of $\operatorname{Re}>1 \times 10^{4}$; and the range of $R e$ changing from $2 \times 10^{3}$ to $1 \times 10^{4}$ corresponds to a mixed flow regime.

In order to not complicate excessively engineering calculations, an approximation formula to calculate the heat exchange coefficient is frequently used:

$H=a+b \sqrt{U}$,

where $a$ and $b$ are the constants, determined from the condition of the best agreement with the data of certain experiment. In most practical cases the heat exchange coefficient is determined experimentally.

Using the approach suggested in [39], the solution of Eq. (2) with boundary conditions ( 3 ) is as follows:

$\left\{\begin{array}{l}-L \leq x<-l: T-T_{a m b}=\left(T_{(-l)}-T_{a m b}\right) \exp \left(\frac{U \rho c(l+x)}{2 \lambda}\right) \frac{\operatorname{sh}(\xi(L+x))}{\operatorname{sh}(\xi(L-l))} ; \\ -l \leq x \leq l: \\ T-T_{a m b}=\frac{\left(T_{l}-T_{a m b}\right) \exp \left[-\frac{U \rho c(l-x)}{2 \lambda}\right] \operatorname{sh}(\xi(l+x))+\left(T_{(-l)}-T_{a m b}\right) \exp \left[\frac{U \rho \rho(l+x)}{2 \lambda}\right] \operatorname{sh}(\xi(l-x))}{\operatorname{sh}(2 \xi l)}+\frac{P}{2 l H p} \\ l<x \leq L: T-T_{a m b}=\left(T_{l}-T_{a m b}\right) \exp \left(-\frac{U \rho c(l-x)}{2 \lambda}\right) \frac{\operatorname{sh}(\tilde{\xi}(L-x))}{\operatorname{sh}(\xi(L-l))},\end{array}\right.$

where $\xi=\left[(U \rho c / 2 \lambda)^{2}+(H p / \lambda S)\right]^{1 / 2}$.

In this solution the temperatures at the ends of the heater $T_{(-l)}$ and $T_{l}$ are unknown. Let us define the temperatures at the ends of the heater, as

$\left\{\begin{array}{c}T_{l}=T_{0}+\delta T \\ T_{(-l)}=T_{0}-\delta T,\end{array}\right.$

where $T_{0}$ is the temperature at the center of the heater with $x=0$, $\delta T>0$. Obviously this is a rough assumption. Nevertheless in this theoretical study we do not claim a quantitative agreement of results from our analytical model with the experimental data. It is important for us to obtain a qualitative description of the process. 
From (8) it follows that the temperature at the center of the heater is given by

$T_{0}-T_{a m b}=\frac{\left(T_{l}-T_{a m b}\right) \exp \left[-\frac{U \rho c l}{2 \lambda}\right]+\left(T_{(-l)}-T_{a m b}\right) \exp \left[\frac{U \rho c l}{2 \lambda}\right]}{2 c h(\xi l)}+\frac{P}{2 l \mathrm{Hp}}$

Substituting our assumption (9) into this formula, we get a formula for $\delta T$ stated as follows

$\delta T=\frac{\left(T_{0}-T_{a m b}\right)\left(\operatorname{ch}\left(\frac{U \rho c l}{2 \lambda}\right)-\operatorname{ch}(\xi l)\right)+\frac{P}{2 l H p} \operatorname{ch}(\xi l)}{\operatorname{sh}\left(\frac{U \rho c l}{2 \lambda}\right)}$.

Let us examine a frequently seen in practice case of the heating element working in the mode of constant temperature. Operating in this mode the average temperature of the heater $\bar{T}_{h}$, at different values of fluid flow velocity $U$, is kept constant by setting the necessary electrical power $P$ supplied to the heater. To keep the calculation simple let us make another assumption that the average temperature of the heater $\bar{T}_{h}$, determined in practice, coincides with the temperature at the center of the heating element $T_{0}$.

Fig. 3 presents qualitative result of the calculation of steadystate temperature distribution in the membrane $T=T(x)$ while the sensor is in the mode of constant temperature for different gas flow velocity $U=0,0.01$ and 0.1 .

The temperature difference between the temperature sensitive elements located symmetrically downstream and upstream with reference to the heater is defined as

$\Delta T=T\left(x_{s}\right)-T\left(-\chi_{s}\right),\left(x_{s}>l\right)$.

As follows from Fig. 3, in the absence of directed gas flow $(U=0)$ the steady-state temperature distribution in the membrane $T=T(x)$ is presented as an even function and the temperature difference $\Delta T=0$. The directed gas flow $(U \neq 0)$ changes the temperature distribution in the membrane both in areas downstream and upstream with reference to the heater and in the heating element; and the temperature difference $\Delta T \neq 0$. The temperature difference rises with the increase of velocity of the gas flow. The figure also shows that the temperature of the temperature sensitive element located downstream close enough to the heater can exceed the average temperature of the heater.

\section{Microsensor}

The thermal flow sensor must meet fairly strict functional, technological and mechanical requirements. The important

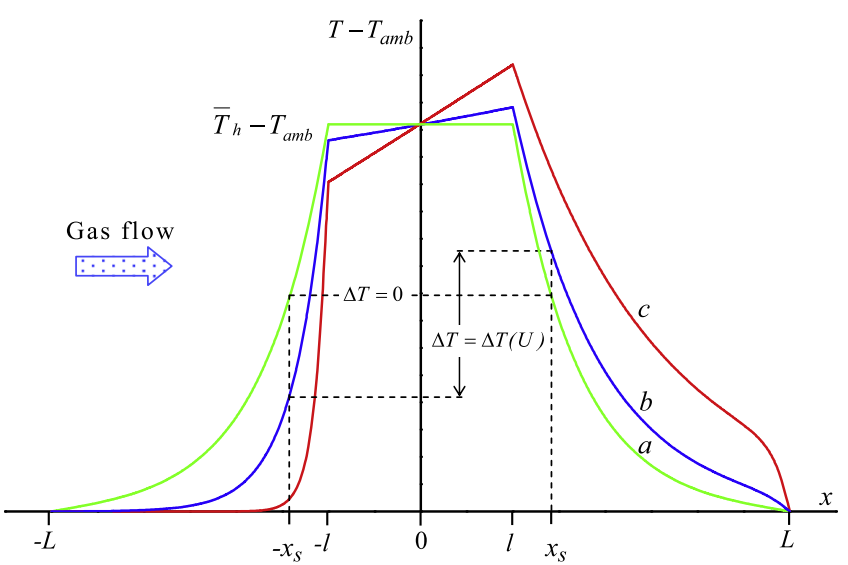

Fig. 3. Steady-state temperature distribution in the membrane $T=T(x)$, while the calorimetric flow sensor is in the mode of constant temperature for different gas flow velocity $U=0$ (a); 0.01 (b) and 0.1 (c). functional requirements are high level of the valid signal, rapid response and low energy consumption. The sensor must be fairly durable and reliably protected from damage and contamination. The surface of the sensor must be chemically passive. The sensor manufacturing technology must contain the maximum number of standard microelectronic production operations.

In this study the equipment used for creating the sensor is defined by requirements for manufacturing integrated microcircuits. Manufacturing is performed in the microelectronic production in clean rooms and using standard equipment for the micro-electromechanical systems formation.

The microsensor is formed on monocrystalline silicon plate. The manufacturing technology is integral, i.e. micromachining batch of plates containing hundreds of sensors on each plate is carried out in one manufacturing process, which makes possible to achieve uniformity of the parameters of the microsensor and low manufacturing cost of a single microsensor in a mass production can be obtained. Fig. 4 shows a plate with sensors after micromachining (planar and non-planar sides).

Initially, a raw plate undergoes hydro mechanical and chemical treatments to remove the technical contamination. At this stage using the method of double-sided lithography two-way labels are formed. Labels are used to combine topologies of opposite sides of the plate in the process of photolithography in subsequent operations.

At the next stage the oxidation of the plate up to $1.2-2.0 \mu \mathrm{m}$ in thickness on both sides is performed in order to obtain the etching mask membrane and insulation of the electrical circuit from the substrate. Afterwards a silicon nitride layer around $0.15 \mu \mathrm{m}$ thick is applied to the surface of the planar side of the plate.

The following layer applied on a planar side of the plate is a doped polycrystalline silicon in order to form electric conductors, resistance of which depends on the temperature. For this purpose by gas-phase method the surface of silicon nitride is coated with $1 \mu \mathrm{m}$ thick polycrystalline silicon; then polysilicon layer is alloyed with a dope. Alloying is performed according to regime which ensures the highest temperature coefficient resistance (TCR) with a sufficiently high level of linear dependency between resistance and temperature. The configuration of heating and four temperature sensitive resistors located in the membrane, as well as one resistor on the edge of the sensor used for measuring air temperature, are formed in this layer. The conductors system in order to put this configuration in the external circuitry for recording and processing the valid signal is also formed at this stage.

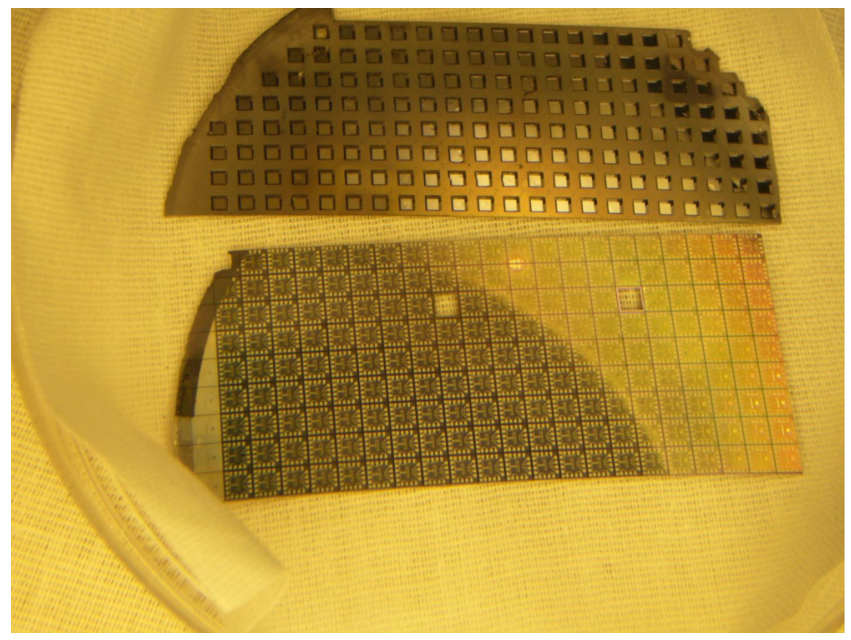

Fig. 4. The silicon plate after micromachining. The planar and non-planar sides. 


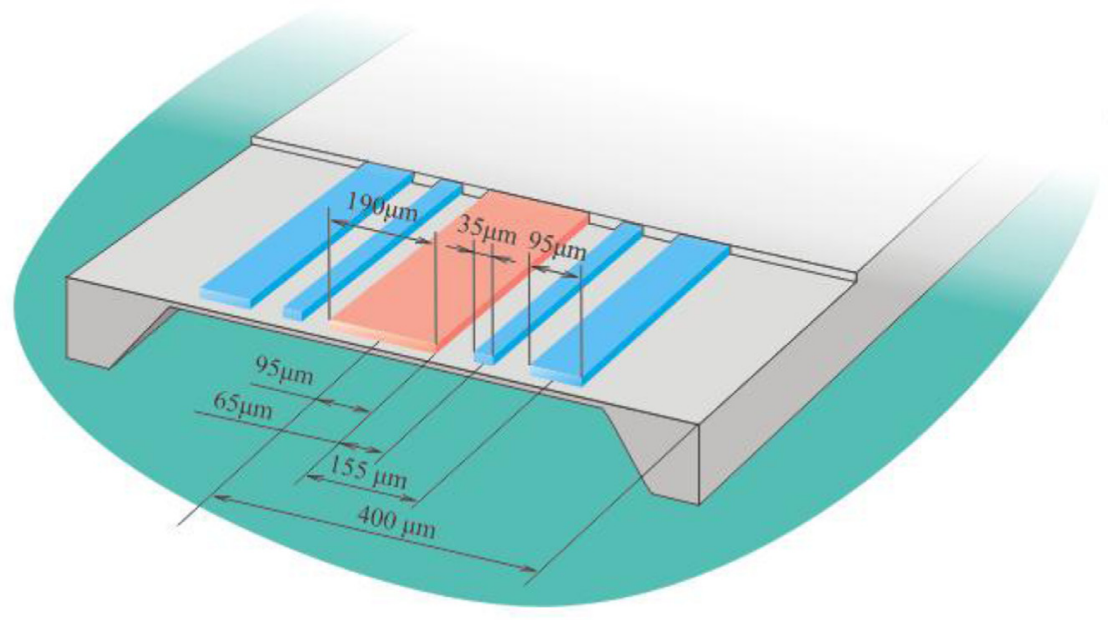

Fig. 5. Location of the heater (center) and four temperature sensitive resistors in the membrane.

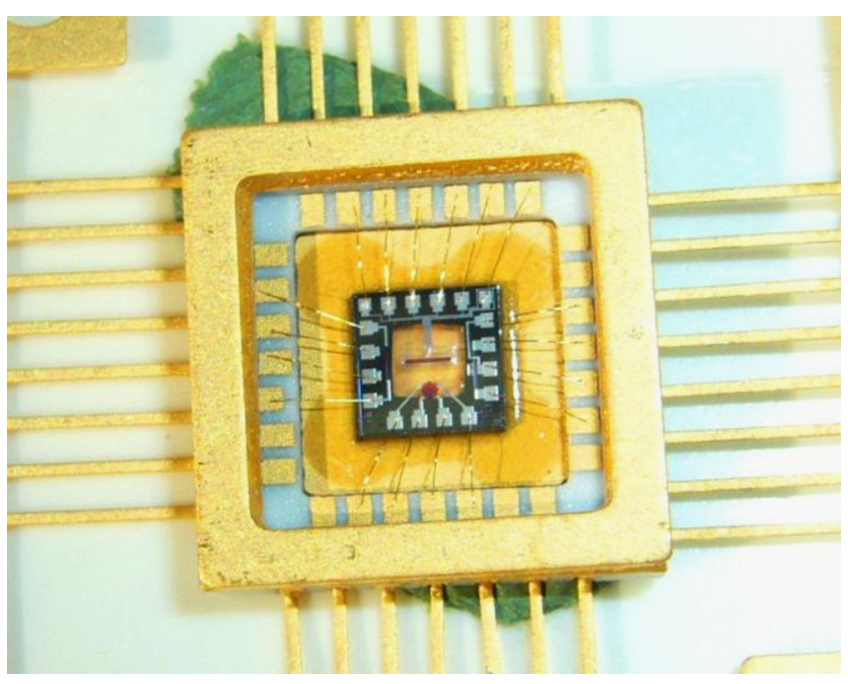

Fig. 6. Microsensor in a testing case.

The electrical circuit in the polycrystalline silicon layer is formed by using the photolithography method. Fig. 5 shows the location of the heater (in the center) and four temperature sensitive resistors in the membrane. The sizes of the heater and the temperature sensitive resistors, as well as their location in the membrane, are determined on the basis of preliminary theoretical calculations according to developed analytical model and features of the available technology and equipment.

After this $0.2 \mu \mathrm{m}$ thick silicon nitride is deposited on the formed surface of the planar side of the plate. Thus, the conductive layer is "packed" into impermeable cover of silicon nitride and is not under the threat of chemical effect of the environment and the technological reagents.

At the final stage the plate undergoes micromachining (Fig. 4). With the use of previously formed labels a photolithography process is carried out in order to obtain the topology of the plate's surface as a whole, in particular lines for scribing and membranes etching masks are formed. In the membrane area on the nonplanar side of the plate the monocrystalline silicon is etched to $10-20 \mu \mathrm{m}$ thickness, which is sufficient to provide mechanical strength to carry out further operations.

At this stage bonding areas are formed by vacuum deposition of aluminum to subsequently put microsensor in external circuitry. To divide into individual crystals, on each of which a separate microsensor is formed, diamond scribing of the plate is performed.

The final step is the complete removal of the monocrystal silicon in membrane area to reduce the "parasitic" effect of the substrate and to remove the mechanical stresses conditioned by differences in the temperature of various materials' films formations. Thus, the bearing element of the membrane is nitride and oxide of silicon. As a result the total thickness of the membrane with circuitry located inside is less than $2 \mu \mathrm{m}$.

Fig. 6 presents a microsensor in a testing case. The figure shows that the membrane is so thin that the gilded cover underneath it can be clearly seen. According to the measurements a typical resistance of the temperature sensitive resistors under normal climate conditions is: $498 \Omega$ for the heater; $4469 \Omega$ for the first resistor (Fig. 5, left to right), 3399, 3383 and $4452 \Omega$ for the second, third and fourth resistors, respectively. The resistors' temperature coefficient of resistance (TCR) $\alpha$ is $1.310^{-4}\left(\mathrm{~K}^{-1}\right)$.

\section{Conclusion}

The main results of the performed study are the analytical model of the calorimetric flow sensor and a prototype of microsensor for mass air flow meter.

The developed analytical model of the sensor is suitable for engineering calculations. The design and manufacturing technology of the microsensor enable mass production, subsequent device assembly and reliable operation as well. The obtained results are important for development, production and optimization of the thermal flow microsensors. The next stage of the research is the development and design of the mass air flow meter for automobile industry based on the thermal flow microsensor presented in this paper.

\section{Acknowledgments}

This study was partly supported by the Grant of the Russian government No. 11.G34.31.0064.

\section{Appendix A. Supporting information}

Supplementary data associated with this article can be found in the online version at http://dx.doi.org/10.1016/j.flowmeasinst.2013. 01.006. 


\section{References}

[1] Beeby S, Ensell G, Kraft M, White N. MEMS mechanical sensors. Boston, London: Artech House Inc; 2004.

[2] Encyclopedia of Micro- and Nano-Fluidics. Dongqing Li, editor. NY: Springer; 2008.

[3] Elwenspoek MC. Thermal flow micro sensors. In: Proceedings of the 1999 international semiconductor conference, Sinaia, Romania; 1999, p. 423-35.

[4] Huang L, Chen C, Yao Y, Wang G. US Patent No. 7878056, 1 February 2011; Wang G, Chen C, Yao Y, Huang L. US Patent No. 7536908, 6 May 2009; Yamashita Y, Oshima Y. US Patent No. 7549332, 23 June 2009; Speldrich JW. US Patent No. 7603898, 20 October 2009; Plowman TE, Jewett WR. US Patent No. 7500392, 10 March 2009; Nakano H, Watanabe I, Yamada M, Matsumoto M. US Patent No. 7360415, 22 April 2008;

Higashi RE, Satren EA. US Patent No. 7408133, 5 August 2008; Hiroshi N, Masamichi Y, Masahiro M, Izumi W. European Patent No. 2060880 20 May 2009.

[5] Fleming WJ. Overview of Automotive Sensors. IEEE Sensors Journal 2001;1:296-308.

[6] Marek J, Illing M. Microsystems for the automotive industry. In: Proceedings of the international electron devices meeting, San Francisco, CA; 2000, p. 3-8.

[7] 〈http://www.bosch.com〉.

[8] Shin WC, Besser RS. A micromachined thin-film gas flow sensor for microchemical reactors. Journal of Micromechanics and Microengineering 2008;16:731-741.

[9] Scholer L, Lange B, Seibel K, Schafer H, Walder M, Friedrich N, et al. Monolithically integrated micro flow sensor for lab-on-chip applications. Microelectronic Engineering 2005;78-79:164-170.

[10] Sensors Applications. In: Oberg P Ake, Togawa Tatsuo, Spelman Francis A, editors. Sensors in Medicine and Health Care. Weinheim, Berlin: Wiley-VCH; 2004.

[11] Domínguez M, Jiménez V, Ricart J, Kowalski L, Torres J, Navarro S, et al. A hot film anemometer for the Martian atmosphere. Planetary and Space Science 2008;56:1169-1179.

[12] Kang J et al. Comfort sensing system for indoor environment. In: Proceedings of the transducers, Chicago, IL; 1997, p. 311-4.

[13] Van den Berg A, T.S.J. Lammerink. Micro total analysis systems: microfluidic aspects, integration concept and applications.Microsystem technology in chemistry and life science, 194 . Berlin: Springer; 1998 p. 21-49.

[14] Ashauer M, Glosch H, Hedrich F, Hey N, Sandmaier H, Lang W. Thermal flow sensor for liquids and gases based on combinations of two principles. Sensors and Actuators A 1999;73:7-13.

[15] Rodrigues RJ, Furlan R. Design of microsensor for gases and liquids flow measurements. Microelectronics Journal 2003;34:709-711.

[16] De Bree HE, Jansen HV, Lammerink TSJ, Krijnen GJM, Elwenspoek M. Bidirectional fast flow sensor with a large dynamic range. Journal of Micromechanics and Microengineering 1999;9:186-189.

[17] Spazzini PG, Iuso G, Onorato M, Zurlo N. Design, test and validation of a probe for time-resolved measurement of skin friction. Measurement science \& technology 1999;10:631-639.

[18] Ahrens R, Schlote-Holubek K. A micro flow sensor from a polymer for gases and liquids. Journal of Micromechanics and Microengineering 2009;19:074006.

[19] Glaninger A, Jachimowicz A, Kohl F, Chabicovsky R, Urban R. Wide range semiconductor flow sensors. Sensors and Actuators A 2000;85:139-146.

[20] Sabate N, Santander J, Fonseca L, Gracia I, Cane C. Multi-range silicon micromachined flow sensor. Sensors and Actuators A 2004:110:282-288.
[21] Kaltsas G, Petropoulos A, Tsougeni K, Pagonis DN, Speliotis T, Gogolides E, et al. A novel microfabrication technology on organic substrates - application to a thermal flow sensor. Journal of Physics: Conference Series 2007;92:012046.

[22] Tan Z, Shikida M, Hirota M, Sato K, Iwasaki T, Iriye Y. Experimental and theoretical study of an on-wall in-tube flexible thermal sensor. Journal of Micromechanics and Microengineering 2007;17:679-686.

[23] Kim Tae Hoon, Kim Dong-Kwon, Kim Sung Jin. Study of the sensitivity of a thermal flow sensor. International Journal of Heat and Mass Transfer 2009;52:2140-2144.

[24] Sung-Cheoul Roh Yong-Moon, Choi Soo-Yong Kim. Sensitivity enhancement of a silicon micro-machined thermal flow sensor. Sensors and Actuators A 2006;128:1-6.

[25] Nassiopoulou AG. Porous silicon for sensor application. In: Vaseashta A, editor. Nanostructured and advanced materials for applications in sensor, optoelectronic and photovoltaic technology. Netherlands: Springer; 2005. p. 189-204.

[26] Kamis T. Polycrystalline silicon for integrated circuits and displays. Norwell, MA, USA: Kluwer Academic Publishers; 1998.

[27] Pagonis DN, Kaltsas G, Nassiopoulou AG. Fabrication and testing of an integrated thermal flow sensor employing thermal isolation by a porous silicon membrane over an air cavity. Journal of Micromechanics and Microengineering 2004;14:793-797.

[28] Sazhin O. Gas flow through a slit into a vacuum in a wide range of rarefactions. Journal of Experimental and Theoretical Physics 2008;107: $162-169$.

[29] Sazhin O. Rarefied gas flow through a channel of finite length into a vacuum. Journal of Experimental and Theoretical Physics 2009;109:700-706 Erratum 2010; 111: 1054.

[30] Varoutis S, Valougeorgis D, Sazhin O, Sharipov F. Rarefied gas flow through short tubes into vacuum. Journal of Vacuum Science and Technology A 2008;26:228-238.

[31] Sazhin OV, Borisov SF, Sharipov F. Accommodation coefficient of tangential momentum on atomically clean and contaminated surfaces. Journal of Vacuum Science and Technology A 2001;19:2499-2503 Erratum 2002; 20: 957.

[32] Sazhin OV, Borisov SF. Influence of the state of a surface on the formation of a rarefied gas flow in a channel. Journal of Engineering Physics and Thermophysics 2001;74:1232-1238.

[33] Sazhin O. Impact of the gas-surface scattering and gas molecule-molecule interaction on the mass flow rate of the rarefied gas through a short channel into a vacuum. Journal of Vacuum Science and Technology A 2010;28:1393-1398.

[34] Sazhin O, Kulev A, Borisov S, Gimelshein S. Numerical analysis of gas-surface scattering effect on thermal transpiration in the free molecular regime. Vacuum 2008;82:20-29.

[35] Sazhin OV, Kulev AN, Borisov SF. Role of the surface structure in formation of a rarefied gas flow in a channel. Journal TermoPhysics and Aeromechanics 2001;8:391-399 (in Russian).

[36] Sazhin O. Pressure-driven flow of rarefied gas through a slit at a various pressure ratios. Journal of Vacuum Science and Technology A 2012;30:021603.

[37] Lammermk TSJ, Tas NR, Elwenspoek M, JHJ Flultman. Micro-liquid flow sensor. Sensors and Actuators A 1993;37-38:45-50.

[38] External Flow, In: Incropera Frank P, DeWitt David P, Bergman Theodore L, Lavine Adrienne S, editors. Fundamentals of Heat and Mass Transfer, 6th edition, Danvers, MA: Hardcover; 2007, p. 401-85.

[39] Carslaw HS, Jaeger JC. Conduction of heat in solid. Oxford: Clarendon Press; 1959. 